\title{
ОБ ЭКОНОМИЧЕСКОМ ОБОСНОВАНИИ РЕШЕНИЙ, СВЯЗАННЫХ СО СБОРОМ ТВЕРДЫХ КОММУНАЛЬНЫХ ОТХОДОВ
}

\author{
М.П. Цвиль ${ }^{*}$
}

Предложены авторские методики расчета экономических показателей, связанных со сбором и вывозом твердых коммунальных отходов. Особенность методик заключается в применении некоторых подходов пространственной экономики для привязки экономических показателей к городскому ландшафту. В частности, рассмотрены возможности использования в расчетах географических координат с целью оптимизации месторасположения объектов, оценки расстояний, скорости движения, затрачиваемого времени в процессе сбора и вывоза коммунальных отходов на полигон. С помощью методик на нескольких примерах установлена стоимость вывоза коммунальных отходов из г. Минска в расчете на одного жителя, определены основные факторы, влияющие на изменение данного показателя.

Ключевые слова: твердые коммунальные отходы, пространственная экономика, нормирование времени.

JEL классификация: Q53, R41, R53.

DOI: $10.46782 / 1818-4510-2021-4-72-88$

Материал поступил 19.11.2021 2.

Проблематика обращения с отходами широко обсуждается в научной литературе и специальных публикациях, однако ввиду постоянных технологических изменений в отрасли, быстрого обновления стандартов проводить экономическое обоснование инвестиционных и текущих решений в этой сфере довольно непросто.

На первый взгляд, проблему обращения с твердыми коммунальными отходами (ТКО) трудно назвать стратегически важной для экономики, поскольку сама отрасль занимает сравнительно невысокую долю в валовом выпуске и валовой добавленной стоимости. В классификаторе ОКРБ 005$2011^{1}$ данный вид деятельности включен в

${ }^{1}$ Общегосударственный классификатор Республики Беларусь ОКРБ 005-2011 «Виды экономической деятельности». URL: https://www.belstat.gov.by/klassifikatory/ obschegosudarstvennye-klassifikatory-respubliki-belarusispolzuemye-dlya-zapolneniya-gosudarstvennoi-statisticheskoiotchetnosti/obschegosudarstvennyi-klassifikator-okrb-005-2011vidy-ekonomicheskoi-deyatelnosti/ секцию Е - Водоснабжение; сбор, обработка и удаление отходов, деятельность по ликвидации загрязнений. При этом непосредственно к деятельности по обращению с отходами относятся только группировки 381 - Сбор отходов, а также 382 - Обработка, удаление и захоронение отходов. Обращение с коммунальными отходами исключает группировки «Обработка, обезвреживание, удаление и захоронение опасных отходов», «Разборка машин и оборудования, не подлежащих восстановлению», «Переработка отходов и лома черных и цветных металлов».

Вся секция Е занимает 0,8\% в объеме произведенной валовой добавленной стоимости и $0,7 \%$ в объеме ВВП $^{2}$, соответственно доля группировок 381 и 382 в ВВП крайне невелика. Исключив группировки видов де-

${ }^{2}$ URL: https://www.belstat.gov.by/upload-belstat/uploadbelstat-excel/Oficial_statistika/Godovwe/VVP_po_VED_ stryktura-2019.xlsx

* Цвиль Мария Павловна (belaruscn@vip.sina.com). Контактный офис Республики Беларусь (г. Циндао, КНР). https:// orcid.org/0000-0002-0487-152X 
ятельности, связанных с обработкой опасных отходов и металлов, получим еще меньшее значение доли в экономике тех видов деятельности, которые затрагивают обращение с коммунальными отходами.

Между тем совершенствование практики обращения с коммунальными отходами намечено в перечне задач по достижению Целей устойчивого развития, заявленных Республикой Беларусь, а именно 3 :

- задача 6.3. К 2030 г. повысить качество воды посредством уменьшения загрязнения, ликвидации сброса отходов и сведения к минимуму выбросов опасных химических веществ и материалов, сокращения вдвое доли неочищенных сточных вод и значительного увеличения масштабов рециркуляции и безопасного повторного использования сточных вод во всем мире;

- задача 11.6. К 2030 г. уменьшить негативное экологическое воздействие городов в пересчете на душу населения, в том числе посредством уделения особого внимания качеству воздуха и удалению городских и других отходов;

- задача 12.3. К 2030 г. сократить вдвое в пересчете на душу населения количество пищевых отходов на розничном и потребительском уровнях и уменьшить потери продовольствия в производственно-сбытовых цепочках, в том числе послеуборочные потери;

- задача 12.4. К 2020 г. добиться экологически рационального использования химических веществ и всех отходов на протяжении всего их жизненного цикла в соответствии с согласованными международными принципами и существенно сократить их попадание в воздух, воду и почву, чтобы свести к минимуму их негативное воздействие на здоровье людей и окружающую среду;

- задача 12.5. К 2030 г. существенно уменьшить объем отходов путем принятия мер по предотвращению их образования, их сокращению, переработке и повторному использованию.

Семнадцать Целей устойчивого развития и 169 подчиненных им задач, которые

${ }^{3}$ Цели устойчивого развития в Беларуси. URL: https:/
/sdgs.by/ необходимо решить к 2030 г., стали составной частью Повестки дня в области устойчивого развития, принятой ООН в 2015 г. Приверженность Республики Беларусь осуществлению Повестки-2030 закреплена, в частности, Указом Президента Республики Беларусь от 25 мая 2017 г. № $181^{4}$ и подтверждена конкретными действиями по реализации Повестки-2030 на национальном уровне. Исходя из высокой значимости деятельности, связанной со сбором, обработкой и утилизацией твердых коммунальных отходов, для достижения заявленных Целей устойчивого развития данная отрасль экономики представляется приоритетной в части выделения финансовых ресурсов на технологическую модернизацию, а также разработки научных подходов, обеспечивающих анализ и планирование экономики отрасли. В этой связи актуальным представляется вопрос методического обеспечения обоснования решений по обращению с ТКО.

\section{Методологические подходь к әкономическому обоснованию решений по обращению с коммунальными отходами}

Инновации в сфере обращения с коммунальными отходами внедряются неравномерно в различных регионах мира. Экономики Европейского союза вкладывают значительные финансовые ресурсы для технологической модернизации отрасли, ориентируясь на решение задач Повестки дня в области устойчивого развития; развитие отрасли в странах Юго-Восточной Азии связано с бурным ростом мегаполисов. Остальные регионы мира несколько отстают в темпах модернизации сектора обращения с коммунальными отходами.

В этой связи не случайно, что современные исследования, посвященные экономическим аспектам обращения с ТКО, акцентируют внимание на изучении международного опыта практики обращения с отходами, а также международных сопоставлениях (Губернаторов, Ломов, 2020). При

${ }^{4}$ Указ Президента Республики Беларусь от 25 мая 2017 г. № 181 «О Национальном координаторе по достижению Целей устойчивого развития». URL: https://pravo.by/ document/?guid $=3961 \&$ p0 $=$ P31700181 
анализе зарубежного опыта обращения с отходами на передний план, как правило, выходит вопрос о способе их переработки и утилизации. Этот вопрос прежде всего технологический и экологический, экономика переработки полностью определяется применяемыми технологиями, которые постоянно развиваются и окончательно не стандартизированы.

Например, опыт Швеции показывает, что лишь 0,5\% бытовых отходов подвергается захоронению, 50\% используется для рекуперации энергии, $34 \%$ - для рециклинга материалов (Сысоев, 2020). В Беларуси основная масса отходов подвергается захоронению. Изучив передовой зарубежный опыт, исследователи предлагают широко использовать его в практике обращения с отходами в Беларуси, начиная с приближения методологии статистического учета к европейской (Шершунович, Точицкая, 2018), затем перейти к европейским правовым нормам, регламентирующим обращение с отходами (Сачек, Точицкая, Батова, 2018), и в конечном итоге внедрить необходимые технологические инновации через реализацию инвестиционных проектов.

При этом логичен вопрос: насколько экономически обоснованным окажется внедрение европейского опыта обращения с отходами для Беларуси, если принять во внимание различия в доступе к финансовым ресурсам; энергообеспеченности; фондовооруженности; плотности населения? Например, несмотря на некоторую схожесть Беларуси и Швеции в части численности населения, выбранной модели социальноэкономического развития, климатических условий, перенять шведский опыт в полном объеме пока что не имеет смысла. Ввиду относительной дешевизны и достаточности электрической и тепловой энергии в Беларуси использование отходов для ее рекуперации вряд ли окажется целесообразным, а наиболее дешевыми и наименее капиталоемкими (что особенно важно в условиях ограниченности финансовых средств) способами обращения с отходами окажутся захоронение, сжигание или, в крайнем случае, переработка.

Еще одной важной проблемой представляется определение субъекта принятия решений, для которого разрабатываются методики экономического обоснования мер по обращению с отходами. Принципиально важно знать, на кого ориентированы исследования зарубежной практики обращения с ТКО, кто впоследствии будет финансировать и реализовывать проекты по развитию отрасли.

Сегодня на рынке работают как государственные, так и частные операторы по вывозу мусора, услуги которых в конечном итоге оплачивает население. При этом государство полностью регламентирует развитие отрасли, начиная от выбора частных операторов, формирования ценовой политики и заканчивая выбором проектов по переработке и утилизации отходов. Такая система не всегда способствует прозрачности и возможности общественного контроля над экономическими субъектами, часто ограничивает конкуренцию. Населению как конечному потребителю услуг по утилизации ТКО логично знать процесс формирования их цены, а также, по возможности, самим участвовать в принятии некоторых решений.

Определенным новшеством в сфере обращения с отходами могло бы стать содействие государства в реализации социально значимых инициатив населения, что позволило бы перенести часть решений и затрат на локальный уровень местного самоуправления, а также повысить экономическую эффективность принимаемых решений.

Под социально значимой инициативой, как правило, понимается самостоятельная мотивационная активность членов социума, направленная на решение какой-либо существующей проблемы общества ${ }^{5}$. Некоторые из таких инициатив становятся известными далеко за пределами своего региона и получают финансовую поддержку международных организаций. Например, инициатива по интеграции систем здравоохранения и социального обеспечения, выдвинутая жителями финского г. Тесома, получила поддержку Всемирной организации здравоохранения. Однако «осязаемый» результат в виде экономического или соци-

${ }^{5}$ URL: https://www.bsuir.by/ru/molodyozhnyeinitsiativy-i-proekty 
ального эффекта от реализации данной инициативы пока что не зафиксирован 6 .

В Беларуси, например, под эгидой Министерства экономики, а также Европейского союза и ПРООН проведен конкурс «Поддержка экономического развития на местном уровне в Республике Беларусь», в рамках которого должны быть рассмотрены и обеспечены финансовыми ресурсами кластерные и социально значимые инициативы граждан и юридических лиц в регионах страны. Инициативы, представленные в конкурсе, направлены на решение конкретных задач регионального развития Беларуси, а также какой-либо социальной проблемы, развитие инклюзии или поддержку социально уязвимых групп населения. Peализация данных инициатив должна принести экономический, социальный и экологический эффекты ${ }^{7}$, однако методика их оценки нигде четко не прописана.

Методическое обеспечение экономических расчетов, связанных с организацией обращения с отходами, обычно базируется на использовании широкого спектра нормативных показателей, закрепленных стандартами в сфере строительства, жилищно-коммунального хозяйства, общественного питания, медицины, технологий и пр. Особенно важно неукоснительное соблюдение стандартов при обращении с опасными отходами, но и для обычных ТКО регламентируются морфологический состав, физические свойства, нормы образования и накопления. Корме того, устанавливается предельная дальность вывоза отходов в зависимости от эксплуатационных характеристик мусоровозов; по ряду технических показателей определяется целесообразность двухэтапного процесса вывоза мусора с использованием мусороперегрузочных станций ${ }^{8}$. Многие из нормативов обосновывались еще в 1980-х годов, поэтому с учетом совершенствования техники, технологий, законодательства и социальных стан-

${ }^{6}$ URL: https://apps.who.int/iris/bitstream/handle/10665/ 324913/php-4-4-688-698-rus.pdf?sequence=1\&isAllowed=y

7 URL: https://www.belta.by/society/view/klasternye-isotsialno-znachimye-initsiativy-v-belarusi-poluchat-podderzhkupo-proektu-esproon-393873-2020/

8 Добросердова Е.А., Федорова С.Ф. 2018. Организащия и обращение с твердыми бытовыми отходами: учебное пособие. Казань: Издательство Казанского государственного архитектурно-строительного университета. дартов следует провести их научно обоснованный пересчет.

Сегодня организация обращения с ТКО относится к предмету исследований таких отраслей науки, как экология и природопользование, экономика, логистика, градостроительство и пр., отсюда сложное переплетение различных отраслей науки в решении прикладных задач вызывает немало трудностей в применении научных подходов на практике. Поэтому неудивительно, что основным способом проведения экономических расчетов в отрасли является использование нормативных показателей. Тогда возникает вопрос: как можно рассчитать сами нормативы? Для этого требуется методология, совокупность научных подходов и принципов из различных отраслей науки, применение которых позволяет, опираясь на значения частных технических и экономических показателей, изменяющихся по мере совершенствования материально-технической базы, рассчитывать нормативы с целью дальнейшего их использования для обоснования частных решений и проектов в сфере обращения с ТКО.

В качестве примера выбора подходящей методологии для решения реальных сложных межотраслевых задач рассмотрим во многом схожую область науки и практики - экономику городского хозяйства, где переплетаются архитектура и градостроительство, экология, информационные технологии, транспортная логистика. В данном случае для описания и планирования экономики города предложено использовать основы пространственной экономики, включающие, к примеру, «правило Ципфа», гравитационные модели, теорию центральных мест Кристаллера, теорию экономического ландшафта Лёша, которые формируют методологию описания структуры городов и задают общие направления для разработки методик в экономике городского хозяйства 9 . Новое дыхание в развитие пространственной экономики как теоретического направления экономической науки привнесли информационные компьютерные технологии. В частности, современные геоинформационные системы (Google Maps; Яндекс. Карты и др.) стали общедоступным сред-

${ }^{9}$ Коробко В.И. 2008. Экономика городского хозяйства: учеб. пособие. Москва: Издательский центр «Академия». 
ством организации бизнеса, они облегчают процессы планирования поездок и поиска мест оптимального расположения объектов, позволяют обосновывать пространственные решения в режиме реального времени. Автоматизация навигации в городах способствует цифровизации сферы городского транспорта и в целом внедрению концепции «умного города».

Поскольку сбор и вывоз мусора осуществляются в городском пространстве, привязаны к численности жителей и расположению зданий, инструменты электронных карт могут послужить хорошим дополнением к любой методике решения практических задач в сфере обращения с отходами. При этом общие подходы пространственной экономики также могут быть использованы в методологическом обосновании решения задач, связанных с обращением с отходами. Подобные задачи и способы их решения, основанные на научно обоснованных подходах, далее рассмотрим на двух примерах.

\section{Оптимизачия размещения площзадок ТКО в городе}

В новых районах города контейнеры ТКО устанавливаются на площадках, расположение которых заранее обосновано и внесено в генплан микрорайона на этапе проектирования. Поэтому проблем, обусловленных неоптимальным размещением контейнеров, обычно не возникает. В частности, пунктом 13 Технического кодекса устоявшейся практики «Охрана окружающей среды и природопользование. Отходы. Правила обращения с коммунальными отходами» ${ }^{10}$ от 2020 г. установлены требования к контейнерным площадкам для сбора коммунальных отходов, среди которых прописано минимальное расстояние в 20 м от площадок до окон жилых домов, а также другие требования. Российскими СаНПиНами прописаны и другие нормы расположения контейнеров, например ограничение по наибольшему расстоянию от площадок до жилых домов (до 100 м), количеству контейнеров на площадке (до 5$)^{11}$.

10 URL: http://www.ecoinv.by/images/pdf/tkp_fond/ \%D0\%A2\%D0\%9A\%D0\%9F_17.11-08-2020_33140.pdf

${ }^{11}$ URL: https://mos-konteiner.ru/article-item/pravilanormativy-ustanovki-musornyh-kontejnerov/
Перечисленные современные требования в обязательном порядке учитываются при проектировании новых жилых районов. Но как быть со старыми районами, которые проектировались при других нормативах, неоднократно перестраивались? Вероятно, в таком случае окажется полезной оптимизация места расположения площадок для ТКО в соответствии с новыми требованиями, а также с учетом рациональных технико-экономических параметров.

Если площадка ТКО не принадлежит определенной организации, например магазину или ресторану, тогда заинтересованными субъектами в их переносе могут оказаться местная администрация, организация оператор по вывозу мусора или местное население. На практике наибольшие трудности связаны с учетом интересов именно местного населения, которое, во-первых, менее организовано, чтобы реализовать свои экономические интересы, а во-вторых, испытывает трудности в формулировке и экономической оценке данных интересов. В рассматриваемом примере подобная экономическая оценка проводится, и основана она на учете личного времени граждан, затрачиваемого на вынос мусора. При этом сам перенос площадки контейнеров ТКО реализуется на основе инициативы граждан микрорайона, а необходимые данные для экономического обоснования такого решения находятся в открытом доступе.

Описание ситуации. В данном примере рассматривается площадка ТКО в Заводском районе г. Минска, расположенная возле домов № 16-22 Партизанского проспекта. При этом она примыкает не к жилым домам, а к территории университета одному из учебных корпусов и парковке, что создает определенные трудности для местных жителей. Из-за жалоб со стороны университета площадку сделали закрытой, что затрудняет доступ к контейнерам; припаркованные машины часто закрывают проход к контейнерам и препятствуют проезду мусоровоза. Предлагается рассмотреть вопрос о ее переносе. Целесообразность такого решения определяется следующими параметрами: 1) при переносе площадки ТКО местные жители смогут существенно сэкономить время на вынос мусора; 2) бу- 
дут соблюдены все санитарные нормы и ограничения; 3) не возникнет дополнительных препятствий и неудобств для вывоза мусора.

В решении данной задачи будет использован подход по выбору оптимального местоположения объекта на карте. Оптимум достигается в точке, для которой расстояние от всех домов минимально - в этом случае жильцы района экономят время на вынос мусора. При поиске оптимума должно учитываться число жильцов в каждом доме. Примем его пропорциональным числу квартир.

\section{Известные подходы к решению задачи.} Основные методы решения задачи размещения объекта на местности, с учетом расстояний до потребителей, описаны в производственном менеджменте и логистике. Один из них - метод центра тяжести, или метод центроида, который позволяет определить оптимальное место расположения объекта - склада, предприятия, центра выдачи заказов, чтобы обеспечить минимальные затраты на транспортировку грузов и учесть местоположения уже существующих производственных или сервисных объектов, расстояния между ними, а также объемы грузов, которые предстоит перевозить ${ }^{12}$. Похожая задача решается при поиске оптимального местоположения вышек мобильных операторов, только вместо координат расположения действующих предприятий указывают координаты нахождения вероятных пользователей услуг сотовой связи - в жилых домах, на автодорогах, других объектах. При использовании метода центроида расположение действующих объектов задается координатами на плоскости ${ }^{13}$.

До появления электронных карт применение метода центра тяжести представляло собой нетривиальную задачу, основной сложностью в решении которой было нанесение действующих объектов на обычной (бумажной) карте и определение их

${ }^{12}$ Куган С.Ф. 2021. Теоретико-методологические основы оценки формирования и выбора путей развития логистических потенциалов регионов Республики Беларусь: диссертация на соискание ученой степени доктора экономических наук по специальности 08.00.05. Минск: БГЭУ.

13 Чейз Р.Б., Джейкобс Ф.Р., Аквилано Н.Дж. 2007. Производственный и операционный менеджент. Москва: Вильямс. С. 655. местоположения, которые могут быть заданы в произвольной системе координат. Ввиду определенных сложностей с обработкой информации применялись упрощенные методы, позволяющие перевести поиск оптимального решения из двумерного пространства в одномерное (Гаджинский, 2004).

В методике оптимального размещения производственных объектов координаты размещаемого объекта задаются в градусах, с указанием широты и долготы. Затем строится целевая функция издержек, с учетом расстояния от точки размещения объекта до действующих объектов, а также стоимости перевозок. Расстояния задаются также в градуcax, при этом они взвешиваются с учетом интенсивности перемещения товаров или услуг и стоимости перемещения между двумя точками, затем определяется суммарная стоимость взаимодействия размещаемого предприятия с действующими предприятиями, в итоге определяется оптимальная точка размещения предприятия по критерию минимума затрат. Для определения точки оптимального размещения с координатами $(x, y)$ решается система линейных уравнений с целевой функцией суммарных затрат, которая должна стремиться к минимуму (Дулесов, Прутовых, 2013).

В части инструментария, используемого в оптимизации размещения объектов на карте, применяется, к примеру, метод построения минимальной охватывающей окружности. Смысл его в том, чтобы найти точку, расстояние от которой до наиболее удаленной от нее точки из предложенного множества точек будет минимальным. Искомая точка - это центр минимальной охватывающей окружности, радиус окружности $r$ - расстояние до наиболее удаленной от центра точки (Гибадуллин, 2015). Функцией оптимизации является минимум расстояния от искомого центра окружности $(x, y)$ до точек с координатами $\left(x_{i}, y_{i}\right)$ :

$$
r=\left(\sqrt{\left(x_{i}-z\right)^{2}+\left(y_{i}-y\right)^{2}}\right) \rightarrow \min .
$$

Дальнейшим развитием модели (1) при решении задач размещения может стать применение весовых коэффициентов для всех точек $\left(x_{i}, y_{i}\right)$, которые будут опреде- 
лять интенсивность взаимодействия с искомым центром окружности $(x, y)$, или затраты, связанные со взаимодействием.

Недостатком рассмотренных выше подходов является указание координат уже существующих $\left(x_{i}, y_{i}\right)$ и новых объектов $(x, y)$ в градусах и дальнейшее проведение расчетов с выдачей оптимального результата в тех же градусах. Реальные расстояния в метрах или километрах от места оптимального размещения до существующих объектов при этом не вычисляются, что затрудняет дальнейшую работу по поиску места расположения объекта, близкого к оптимальному, а также расчеты некоторых экономических показателей. Например, общие затраты времени жильцов района на вынос мусора можно подсчитать, зная точные расстояния от жилых домов до площадки с контейнерами. Именно поэтому задачу поиска оптимального места размещения объекта лучше формулировать сразу с переходом от координат в градусах к расстояниям в километрах и метрах.

В работе (Дулесов, Прутовых, 2012) приводится формула, позволяющая вычислить расстояние между двумя точками (в километрах), зная их географические координаты:

$$
\begin{aligned}
S_{i} & =111,2 \cdot a \cos \left(\sin \left(x_{i}\right) \cdot \sin (x)+\right. \\
& \left.+\cos \left(x_{i}\right) \cdot \cos (x) \cdot \cos \left(y_{i}-y\right)\right),
\end{aligned}
$$

где $S_{i}-$ расстояние между двумя точками на поверхности земли, км;

$x_{i}, y_{i}, \quad$ - широта и долгота $i$-й точки, градусов;

$x, y$ - широта и долгота искомой точки, градусов.

Искомая точка с координатами $(x, y)$ определяется с учетом весовых параметров $W_{i}$ для каждого $i$-го потребителя, при котором $S$ минимально:

$$
S=\sum_{i} W_{i} \cdot S_{i}
$$

где $S$ - суммарная стоимость перевозок, руб.;

$W_{i}-$ стоимость продукции или ресурсов, перевозимых между предприятиями.

Тестирование формулы (2) на электронной карте показало ошибку в сторону увеличения около $+30 \%$ к реальному расстоянию между двумя точками. Однако в целом предлагаемый принцип расчета под- ходит при решении задачи размещения площадок ТКО во дворах жилых районов.

Особенности предлагаемой методики. Представлена методика для поиска оптимального места размещения в жилых дворах площадок контейнеров для ТКО. Методика применима к старым жилым районам, в которых площадки ТКО не были заранее спроектированы и расположены стихийно, без необходимого технико-экономического обоснования.

Для применения методики необходимы следующие инструменты: масштабируемые онлайн-карты с высоким уровнем детализации (3-5 м в 1 см) - Яндекс. Карты, Google Maps или их аналоги; таблицы MS Excel c надстройкой «Поиск решения» или аналогичное ПО со встроенной функцией оптимизации.

В задаче поиска оптимального места размещения объекта - площадки контейнеров ТКО на территории жилого массива - происходит перебор возможных точек размещения объекта с координатами широты $(x)$ и долготы $(y)$. При этом каждый жилой дом $i$ характеризуется собственным месторасположением с координатами $\left(x_{i}, y_{i}\right)$, в градусах.

Пусть фактическое расположение объекта - площадки ТКО - определяется координатами $\left(x_{\phi}, y_{\phi}\right)$. Тогда фактическое расстояние, пройденное в единицу времени жильцами района для выноса мусора, составит:

$$
R A^{\Phi}=\sum_{i}\left(A_{i} \cdot R_{i}^{\phi}\right)
$$

где $R A^{\phi}$ - общее расчетное расстояние, пройденное жильцами района от своих подъездов до площадки с контейнерами ТКО для выноса мусора, км·чел., в единицу времени;

$A_{i}$ - число квартир в доме $i$; предполагается, что объем выносимого из дома мусора пропорционален числу квартир в доме;

$R A_{i}^{\phi}$ - фактическое расстояние от дома $i$ с координатами $\left(x_{i}, y_{i}\right)$ до места расположения площадки контейнеров с координатами $\left(x_{\phi}, y_{\phi}\right)$, км.

Целевая функция оптимального размещения - минимум общего расстояния от подъезда до контейнеров, пройденного жильцами всех квартир всех домов микрорайона: 


$$
R A^{\mathrm{O \Pi T}}=\sum_{i}\left(A_{i} \cdot R_{i}\right) \rightarrow \min
$$

где $R A^{\text {опт }}-$ общее расчетное расстояние, пройденное жильцами района от своих в точке оптимального размещения для выноса мусора, км.чел., в единицу времени; ми $\left(x_{i}, y_{i}\right)$ до нового места расположения площадки контейнеров с координатами $(x, y)$, км.

Для расчета расстояния $R_{i}$ при заданных координатах точек $\left(x_{i}, y_{i}\right)$ и $(x, y)$ в градусах используется формула ${ }^{14}$ : подъездов до площадки с контейнерами ТКО

$R_{i}$ - расстояние от дома $i$ с координата-

ного расположения объекта по формуле (1), однако не пригоден для расчета экономии времени по формуле (7), без которого в дальнейшем невозможно измерять экономическую эффективность решений. Последняя определяется через перемножение сэкономленного времени $T^{\ni}$ на величину средней ставки отработанного времени. Полученное денежное выражение экономии в дальнейшем можно сравнивать с денежными затратами на перенос площадки ТКО.

При расчете нового местоположения площадки ТКО нужно учесть возможные ограничения, в их числе - требование минимального расстояния от контейнеров до жилых домов, а также наличие подъездных путей. Поэтому при $\begin{aligned} R_{i} & =6371 \cdot a \cos \left(\cos \left(\frac{\pi}{180} \cdot\left(90-x_{i}\right)\right) \cdot \cos \left(\frac{\pi}{180} \cdot(90-x)\right)+\sin \left(\frac{\pi}{180} \cdot\left(90-x_{i}\right)\right)\right) \times \\ & \times \sin \left(\frac{\pi}{180} \cdot(90-x)\right) \cdot \cos \left(\frac{\pi}{180} \cdot\left(y_{i}-y\right)\right)\end{aligned}$ невозможности разместить объект в точке с координатами $(x$, y) следует искать местоположение вблигде выражение $\frac{\pi}{180}$ необходимо для преобразования градусов в радианы. Тестирование формулы (6) на карте показало отсутствие погрешности в расчетах, в отличие от формулы (2).

Расчетному значению $R A^{\text {опт }}$ соответствуют координаты $(x, y)$ нового местоположения площадки ТКО, при этом общая годовая экономия времени $T^{\ni}$, в часах в год, затрачиваемого жильцами района на вынос мусора, окажется равной:

$$
T^{\ni}=\frac{2 \cdot 365\left(R^{\Phi}-R^{\mathrm{O \Pi T}}\right)}{v \gamma},
$$

где $v$ - средняя скорость пешехода, км/час;

$\gamma$ - принятая средняя частота выноса мусора, дней;

коэффициент 2 в числителе означает движение от дома к площадке и в обратном направлении; 365 - число дней в году.

Описанный ранее метод центроида ${ }^{15}$ позволяет оценить координаты оптималь-

14 URL: https://progi.pro/formula-excel-dlyavichisleniya-rasstoyaniya-mezhdu-neskolkimi-tochkami-sispolzovaniem-koordinat-latlon-219684

${ }_{15}$ Куган С.Ф. 2021. Теоретико-методологические основы оценки формирования и выбора путей развития логистических потенциалов регионов Республики Беларусь: диссертация на соискание ученой степени доктора экономических наук по специальности 08.00.05. Минск: БГЭУ. зи данной точки, при котором соблюдаются все ограничения. Затем для найденного субоптимального местоположения с координатами $\left(x^{\prime}, y^{\prime}\right)$ считаются показатели $R A^{\text {Опт' }}$ и $T^{9^{\prime}}$, окончательное решение принимается при сопоставлении экономии $T^{\vartheta^{\prime}}$ с единовременными затратами.

Общий алгоритм рационального размещения площадки ТКО приведен на рис. 1. На первом этапе оценивается взвешенная сумма расстояний от фактического местоположения площадки до жилых домов; на втором этапе находится оптимальное местоположение площадки, рассчитываются общие затраты времени и определяется целесообразность переноса площадки. Если перенос целесообразен, тогда с учетом всевозможных ограничений определяется субоптимальное местоположение, вновь пересчитываются затраты времени и принимается окончательное решение о переносе.

Решение задачи с реальными данными. В табл. 1 внесены географические координаты жилых домов (широта и долгота), для которых предназначена площадка TКО, а также координаты ее фактического местоположения, полученные с помощью сервиса Яндекс. Карты. В ячейки таблицы Excel E3:Е7 введена формула расчета рас- 
Анализ фактического размещения объекта: расчет взвешенной суммы расстояний $R A^{\phi}$

Поиск координат оптимального размещения объекта $(x, y)$, расчет взвешенной суммы расстояний $R A^{\text {опт }}$

Расчет сэкономленного времени жителей района $T^{\ni}$ при переносе площадки ТКО, затрат на перенос объекта

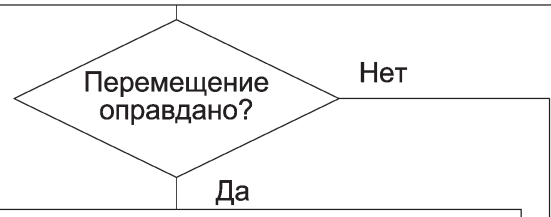

Проверка ограничений при размещении, размещение объекта в месте, близком к оптимальному, поиск субоптимальных координат $\left(x^{\prime}, y^{\prime}\right)$, расстояний $R A^{\text {опт' } и ~ э к о н о м и и ~} T^{\vartheta^{\prime}}$

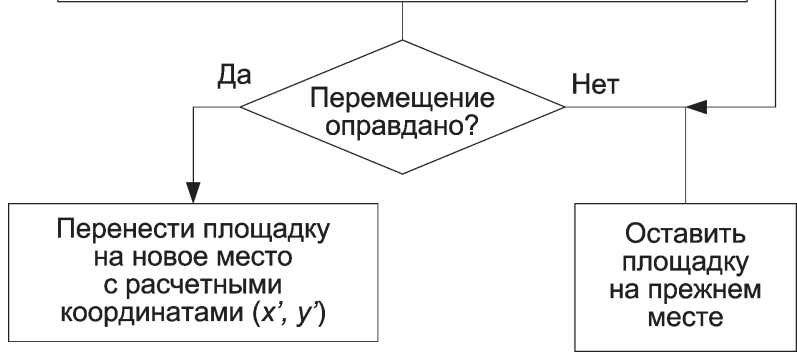

Рис. 1. Алгоритм принятия решения о переносе площадки ТКО

Источник. Авторская разработка.

стояний по координатам точек (6), в ячейки F3:F7 - формула (4). Эти же формулы используются для расчета фактических, оптимальных и субоптимальных значений взвешенной суммы расстояний $R A$.

Для расчета оптимального значения $R A^{\text {опт }}$ использована надстройка MS Excel «Поиск решения». Целевая функция задается в ячейке Е18, область поиска решения (параметры расчета, которые нужно подобрать для поиска оптимума) задается в ячейках В18:C18. Далее используются Яндекс. Карты для визуализации точки $R A^{\text {опт }}$ и ручного поиска субоптимального расположения объекта $R A^{\text {опт }}$, его координаты вносятся в ячейки В27:C 27, значение выводится $R A^{\text {опт }}$ в ячейке $\mathrm{F} 27$.

В доме по адресу Партизанский пр-т, 20 расположено кафе, в этом случае, согласно нормативам, объем отходов возрастает, увеличим его на 20\%. При переносе площадки ТКО в точку субоптимального размещения (оптимального с ограничениями) жителям одного из домов придется обходить свой дом, выходы из подъездов ведут в противоположную сторону. Данное обстоятельство также учтено в расчете, и протяженность маршрута от этого дома до объекта размещения увеличена на 20 м, что отражено в формуле в ячейке Е22.

После переноса площадки ТКО в новое место с координатами B27:C27 общее расстояние, пройденное жильцами района с целью выноса мусора, должно снизиться с 21 до 15 км-чел. При условии, что скорость пешехода $v$ равна 5 км/час, а частота выноса мусора $\gamma$ составит 2 дня, сэкономленное жильцами за 1 год время будет $T^{9^{\prime}}=441$ чел.ччас.

Затраты на перенос площадки для контейнеров можно также оценить в человеко-часах и затем привязать их к стоимостным показателям. Допустим, средняя стоимость рабочего времени составляет около 10 руб./чел.ччас. В этом случае переведем затраты времени в человеко-часах $\mathrm{T}^{{ }^{\prime}}$ к стоимостному показателю, которые составят 4410 руб./год. Теперь, зная приблизительный эквивалент годовых затрат, которые удалось «сэкономить» после переноса площадки ТКО, сопоставим его с единовременными затратами на перенос площадки. Если они окажутся менее 4,4 тыс. руб. (включая материалы, затраты на использование техники, а также другие обязательные выплаты), проект, можно считать, условно «окупится» в течение года.

Предложенная методика является лишь инструментом, использование которого возможно при наличии инициативы, исходящей от жителей района, а также заинтересованных граждан, готовых такую инициативу реализовать. Нужно отметить, что без электронных карт оценить затраты времени на вынос мусора и, следовательно, эффективность решений о размещении площадки ТКО достаточно сложно. Если даже подобные методики оптимизации размещения объектов и разрабатывались раньше, то их реальное практическое применение стало возможным лишь после распространения электронных онлайн-карт.

\section{Определение величины оплаты за вывоз мусора каждым жителем города}

Тарифы на вывоз мусора из жилых районов определяются местной администрацией исходя из условий договора с операто- 
Поиск координат площадки контейнеров ТКО

\begin{tabular}{|c|c|c|c|c|c|c|}
\hline № & $\mathrm{A}$ & $\mathrm{B}$ & $\mathrm{C}$ & $\mathrm{D}$ & $\mathrm{E}$ & $\mathrm{F}$ \\
\hline 1 & Дом $i$, адрес & Широта $x_{i}$ & Долгота $y_{i}$ & $\begin{array}{c}\text { Число } \\
\text { квартир } A_{i}\end{array}$ & $\begin{array}{c}\text { Расстояние до } \\
\text { площадки, км } R_{i}\end{array}$ & $\begin{array}{c}\text { С учетом числа } \\
\text { квартир } R A_{i}\end{array}$ \\
\hline 2 & \multicolumn{5}{|c|}{ Фактическое МП } \\
\hline 3 & Партизанский, 22 & 53,87865 & 27,60581 & 32 & 0,036283 & 1,161062 \\
\hline 4 & Партизанский, 18 & 53,87882 & 27,60486 & 32 & 0,046768 & 1,49658 \\
\hline 5 & Партизанский, 16 & 53,87953 & 27,60363 & 64 & 0,159567 & 10,21228 \\
\hline 6 & Партизанский, 18А & 53,87930 & 27,60459 & 32 & 0,100743 & 3,223761 \\
\hline 7 & Партизанский, 20+20\% & 53,87908 & 27,60554 & 64 & 0,066491 & 5,106544 \\
\hline 8 & - & - & - & 224 & - & - \\
\hline 9 & Координаты ТБО & 53,87850 & 27,60533 & - & $R A^{\phi}$ & 21,20022 \\
\hline
\end{tabular}

\begin{tabular}{|c|l|c|c|c|c|c|}
\hline 11 & \multicolumn{7}{|c|}{ Оптимум } \\
\hline 12 & Партизанский, 22 & 53,87865 & 27,60581 & 32 & 0,06726 & 2,15230 \\
\hline 13 & Партизанский, 18 & 53,87882 & 27,60486 & 32 & 0,03218 & 1,02975 \\
\hline 14 & Партизанский, 16 & 53,87953 & 27,60363 & 64 & 0,10757 & 6,88420 \\
\hline 15 & Партизанский, 18А & 53,8793 & 27,60459 & 32 & 0,04024 & 1,28771 \\
\hline 16 & Партизанский, 20+20\% & 53,87908 & 27,60554 & 64 & 0,03033 & 2,32903 \\
\hline 17 & - & - & - & 224 & - & - \\
\hline 18 & Искомые координаты & 53,87908 & 27,60508 & - & $R A^{\text {опт }}$ & 13,68298 \\
\hline
\end{tabular}

\begin{tabular}{|c|l|c|c|c|c|c|}
\hline 20 & \multicolumn{7}{|c|}{ Оптимум с ограничениями } \\
\hline 21 & Партизанский, 22 & 53,87865 & 27,60581 & 32 & 0,08975 & 2,87205 \\
\hline 22 & Партизанский $18,+20$ м & 53,87882 & 27,60486 & 32 & 0,05212 & 1,66787 \\
\hline 23 & Партизанский, 16 & 53,87953 & 27,60363 & 64 & 0,08351 & 5,34464 \\
\hline 24 & Партизанский, 18А & 53,8793 & 27,60459 & 32 & 0,02433 & 0,77848 \\
\hline 25 & Партизанский, 20+20\% & 53,87908 & 27,60554 & 64 & 0,05854 & 4,49560 \\
\hline 26 & - & - & - & 224 & - & - \\
\hline 27 & Искомые координаты & 53,87908 & 27,60465 & - & $R A^{\text {oпr’ }}$ & 15,15863 \\
\hline
\end{tabular}

Источник. Авторская разработка.

ром, вывозящим ТКО. Однако «справедливая» цена вполне может отличаться от установленного тарифа, и ее размер прежде всего зависит от самого города, от организации логистики бытовых отходов. Ответ на данный вопрос важен как самим жителям, так и администрации города или района, которая в рамках государственно-частного партнерства привлекает к вывозу мусора частные фирмы на условиях тендера. Как определить приемлемую цену, на которую в дальнейшем можно ориентироваться при проведении тендера, если технологии меняются, нормативы устаревают, а в каждом городе существует своя специфика вывоза отходов? При подготовке к заключению договора с оператором нелишним окажется установить приблизительную себестоимость вывоза мусора, заложить приемлемую норму прибыли, учесть основные налоги. В этом случае появится отправная точка для торга с частными организациями на предмет окончательного формирования тарифа.

Вывоз мусора из г. Минска сегодня осуществляется только на один полигон Тростенецкий. Другие полигоны - Северный и Прудище - в настоящее время закрыты. На полигоне также работает мусороперерабатывающий завод, на котором сортируются и перерабатываются стекло, пла- 
стик, бумага и текстиль, а также функционирует установка по выработке биогаза из мусора. Согласно статистике, на полигон ежедневно прибывает около 450 мусоровозов, а ежегодно накапливается 800 тыс. т мусора. Из этого объема на мусороперерабатывающем заводе сортируется около 100 тыс. т мусора, из отсортированных отходов извлекается $14 \%$ вторичного сырья ${ }^{16}$.

Если принять число жителей г. Минска около 2 млн чел., а также установить средний размер ТКО на 1 чел. около 400 кг в год, что характерно для Беларуси (рис. 2), то цифры приблизительно сходятся: действительно, на полигон Тростенецкий ежегодно должно свозиться около 800 тыс. т отходов.

Приведенной выше информации будет определенно недостаточно для оценки стоимости вывоза мусора из г. Минска, даже если известны все затраты, связанные с эксплуатацией парка мусоровозов и захоронением отходов. Во-первых, каждый мусоровоз может сделать 1, 2, 3 или более рейсов из города на полигон и обратно, их точное количество неизвестно и зависит от производительности мусоровоза, скорости и маршрута, по которому он движется. Вовторых, на полигон привозят не только ТКО из жилых микрорайонов, но также отходы организаций, прежде всего торговли и общественного питания, а также строительный и прочий мусор. Организации сами нанимают оператора и оплачивают вывоз

${ }^{16} \mathrm{Ha}$ «грязной» стороне Минска: сколько мусора выбрасывает столица, почему разные контейнеры загружают в одну машину и чем опасны коробки от пиццы. URL: https://realt.by/news/article/25038/

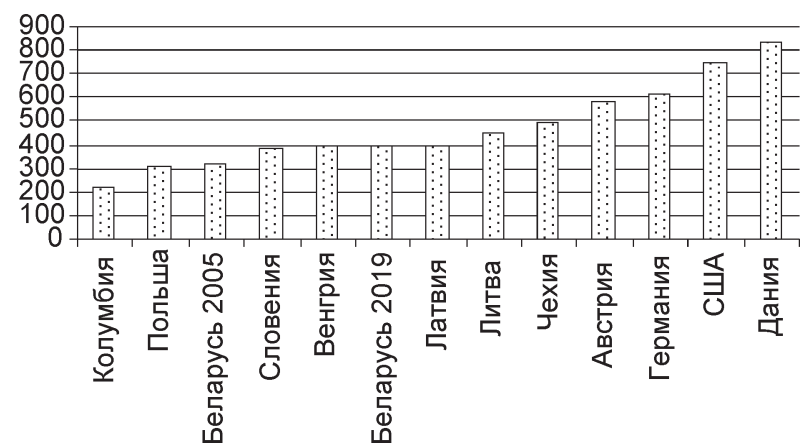

Рис. 2. Статистика образования отходов в Беларуси и других странах, кг ТКО на 1 чел. в год

Источник. Данные ОЭСР за 2018 г., Белстата. мусора, поэтому важно оценить количество отходов, которые образуются только в жилых районах и вывоз которых должны в итоге оплачивать сами жильцы.

Если мы хотим рассчитать, хотя бы приблизительно, стоимость вывоза мусора в расчете на одного жителя Минска, понадобятся следующие данные, включающие ряд технико-экономических показателей:

- нормы образования мусора в расчете на одного жителя многоквартирных домов - эта величина окажется явно меньше 400 кг на 1 чел. в год;

- коэффициенты оборота парка мусоровозов, которые характеризуют число рейсов на полигон и обратно за рабочую смену;

- данные о производительности мусоровоза (для расчета коэффициентов), которые определяют массу перевозимого мусора и зависят от объема бункера и степени уплотнения мусора.

Кроме того, важно исследовать маршруты движения мусоровозов и определить нормы времени на погрузку-разгрузку (методом наблюдения) и проезд до полигона и обратно (можно рассчитать по данным электронной карты).

Полученная информация в дальнейшем используется для оценки итоговых экономических показателей. Для этого необходимы данные о стоимости эксплуатации парка мусоровозов, оплате труда работников, норме прибыли и налогах, выплачиваемых организацией-оператором.

Для расчета перечисленных показателей используются следующие источники информации: данные специализированных интернет-ресурсов, осуществляющих продажу, аренду или лизинг мусоровозов, где можно узнать показатели их производительности, а также цену и стоимость эксплуатации; объявления о работе для определения зарплаты водителей мусоровоза; электронные карты как источник данных о протяженности маршрутов мусоровозов, средней скорости движения. Длительность погрузочно-разгрузочных работ определяется методом наблюдения или хронометража.

Технико-экономические параметры и оценочная стоимость вывоза мусора. В табл. 2 приведены некоторые исходные и расчетные показатели для технико-эконо- 
Технико-экономические показатели, характеризующие вывоз мусора

\begin{tabular}{|c|c|c|c|}
\hline Показатель & $\begin{array}{c}\text { Условное } \\
\text { обозначение }\end{array}$ & $\begin{array}{c}\text { Единица } \\
\text { измерения }\end{array}$ & Описание, источник данных \\
\hline \multicolumn{4}{|c|}{ Исходные данные } \\
\hline $\begin{array}{l}\text { Численность } \\
\text { населения города } \\
\text { (района) }\end{array}$ & $\mathrm{U}_{\mathrm{H}}$ & чел. & $\begin{array}{l}\text { Фактическая или прогнозная численность населения } \\
\text { в населенном пункте. В г. Минске равна } 2009786\end{array}$ \\
\hline $\begin{array}{l}\text { Средняя плотность } \\
\text { ТКО }\end{array}$ & $\rho_{\text {Тко }}$ & $\kappa \Gamma / \mathrm{M}^{3}$ & От 60 до 120, примем равной 90 \\
\hline $\begin{array}{l}\text { Норматив } \\
\text { образования } \\
\text { твердых } \\
\text { коммунальных } \\
\text { отходов }\end{array}$ & $\mathrm{H}_{\mathrm{TKO}}^{\text {год }}$ & $\begin{array}{l}\text { кг / чел. } \\
\text { в год }\end{array}$ & $\begin{array}{l}\text { В } 2019 \text { г. равен 405, включая отходы организаций, которые } \\
\text { вывозят мусор самостоятельно. «Чистые» коммунальные } \\
\text { отходы по нормативу равны } 0,2233 \text { м }^{3} \text { на } 1 \text { чел. в месяц. } \\
\text { С учетом принятой плотности норматив равен } \\
0,2233 \cdot 90 \cdot 12=241\end{array}$ \\
\hline $\begin{array}{l}\text { Объем } \\
\text { евроконтейнера }\end{array}$ & $\mathrm{V}_{\mathrm{K}}$ & $\mathrm{M}^{3}$ & $1,1 \mathrm{M}^{3}$ \\
\hline $\begin{array}{l}\text { Коэффициент } \\
\text { уплотнения }\end{array}$ & $k_{\text {упл }}$ & отн. ед. & $\begin{array}{l}\text { Характеризует степень сжатия мусора в данной модели } \\
\text { мусоровоза, равен отношению объема загруженного } \\
\text { мусора к объему, занимаемому им в мусоровозе после } \\
\text { сжатия. На сайтах производителей установлен как } 0,6-0,8, \\
\text { но это предельные величины. В работе* коэффициенты } \\
\text { уплотнения равны 1,5-2, но при этом берется более высокая } \\
\text { плотность ТКО. Примем равным за среднее }-4,5\end{array}$ \\
\hline Объем мусоровоза & $\mathrm{V}_{\mathrm{MB}}$ & $\mathrm{M}^{3}$ & $\begin{array}{l}\text { Задается в технических характеристиках, равен объему } \\
\text { перевозимого мусора. Варьирует от } 4 \text { до } 24 \mathrm{~m}^{3}\end{array}$ \\
\hline $\begin{array}{l}\text { Коэффициент } \\
\text { неравномерности } \\
\text { накопления } \\
\text { отходов }\end{array}$ & $k_{\mathrm{HHO}}$ & отн. ед. & $\begin{array}{l}\text { Зависит от сезона и прочих факторов, принимается } \\
\text { равным 1,25 }\end{array}$ \\
\hline $\begin{array}{l}\text { Коэффициент } \\
\text { использования } \\
\text { парка }\end{array}$ & $k_{\text {ИП }}$ & отн. ед. & Принимается равным 0,8 .. 0,9 \\
\hline \multicolumn{4}{|c|}{ Расчетные показатели } \\
\hline $\begin{array}{l}\text { Годовой объем } \\
\text { образования } \\
\text { отходов }\end{array}$ & $\mathrm{O}^{\text {год }}$ & т в год & $\mathrm{O}^{\text {Год }}=\frac{\mathrm{H}_{\mathrm{TКО}}^{\text {год }} \cdot \mathrm{\Psi}_{\mathrm{H}}}{1000}=\frac{241 \cdot 2009786}{1000}=484358 \mathrm{~T}$ \\
\hline $\begin{array}{l}\text { Необходимое } \\
\text { число контейнеров }\end{array}$ & $\mathrm{U}_{\mathrm{K}}$ & шт. & $\begin{array}{c}\mathrm{Ч}_{\mathrm{K}}=\frac{\mathrm{O}^{\text {год }} \cdot 1000}{\mathrm{~V}_{\mathrm{K}} \cdot \rho_{\text {тко }} \cdot 313}=\frac{484358 \cdot 1000}{1,1 \cdot 90 \cdot 313}=15631 \text { шт. в год }, \\
\text { где } 313-\text { число рабочих дней в году }\end{array}$ \\
\hline $\begin{array}{l}\text { Число рейсов } \\
\text { заполненных } \\
\text { мусоровозов, } \\
\text { необходимых для } \\
\text { вывоза мусора }\end{array}$ & $\mathrm{Y}_{\mathrm{MB}}^{\text {год }}$ & шт. в год & $\mathrm{\Psi}_{\mathrm{MB}}^{\text {год }}=\frac{\mathrm{O}^{\text {год }} \cdot 1000}{\rho_{\mathrm{TКо}} \cdot \mathrm{V}_{\text {МВ }} \cdot k_{\text {упл }}}=\frac{484358 \cdot 1000}{90 \cdot 18 \cdot 4,5}=66441$ шт. в год \\
\hline $\begin{array}{l}\text { Число } \\
\text { мусоровозов } \\
\text { в парке }\end{array}$ & $\mathrm{U}_{\mathrm{MB}}$ & шт. & $\mathrm{Ч}_{\mathrm{MB}}=\frac{\mathrm{Ч}_{\mathrm{MB}}^{\text {год }} \cdot k_{\mathrm{HнО}}}{313 \cdot k_{\text {ОП }} \cdot k_{\text {ИП }}}$ \\
\hline $\begin{array}{l}\text { Коэффициент } \\
\text { оборота парка }\end{array}$ & $k_{\text {Оп }}$ & $\begin{array}{l}\text { Кругов } \\
\text { за смену }\end{array}$ & $\begin{array}{l}\text { Расчетный показатель, равен числу кругов от места сбора } \\
\text { мусора до полигона и обратно за } 8 \text {-часовой рабочий день }\end{array}$ \\
\hline
\end{tabular}

* Добросердова Е.А., Федорова С.Ф. 2018. Организащия и обращение с твердыми бытовыми отходами: учебное пособие. Казань: Издательство Казанского государственного архитектурно-строительного университета. С. 54, $58,59$.

Источник. URL: https://netmus.ru/press-center/articles/pereschyot-obyoma-tverdyih-byitovyih-othodov-v-ves; URL: https://kommash.by/katalog-avto/musorovozy/musorovozy-s-zadney-zagruzkoy-kuzov-ot-6-do-22-m3 
мических расчетов стоимости вывоза мусора, с указанием источников данных, откуда взяты их значения. Большинство нормативных показателей, таких как плотность отходов, степень уплотнения отходов в мусоровозе, объем контейнеров, приводятся в специальной литературе ${ }^{17}$, но, как отмечалось выше, многие из этих данных устарели. Более точные значения показателей взяты из специализированных сайтов по продаже новых или б/у мусоровозов, сайтов мусорных операторов.

Промежуточной целью всех расчетов является оценка числа машин в парке мусоровозов, необходимого для вывоза мусора из г. Минска. Зная эту цифру, можно рассчитать все остальные затраты по вывозу мусора. Однако для оценки размера парка мусоровозов не хватает еще одного важного показателя - коэффициента оборота парка.

Нормирование рабочего времени и расчет коэффициента оборота парка. Данный показатель зависит от ряда факторов, включая: длительность маршрута, скорость движения, время погрузочно-разгрузочных работ. Это время, в свою очередь, определяется емкостью бункера мусоровоза: чем больше объем мусоровоза, тем дольше он маневрирует и загружается, следовательно, тем меньше коэффициент оборота парка.

Поскольку мусор из г. Минска вывозится только на один полигон, несложно рассчитать по электронной карте точное расстояние и оценить скорость движения на разных участках маршрута, что позволит узнать среднее время движения по маршруту. Среднее расстояние от различных точек расположения контейнеров ТКО в г. Минске до точки выезда за МКАД к полигону оценено экспертным путем, оно составило 15 км. Протяженность маршрута по трассе от МКАД до въезда на полигон «Тростенецкий» - 9,8 км; еще 0,7 км нужно проехать по территории полигона до места разгрузки.

При расчете коэффициента оборота парка проанализирован так называемый «цикл оборота парка» (рис. 3). Допустим, каждый мусоровоз начинает движение от

17 Добросердова Е.А., Федорова С.Ф. 2018. Организащия и обращение с твердыми бытовыми отходами: учебное пособие. Казань: Издательство Казанского государственного архитектурно-строительного университета.

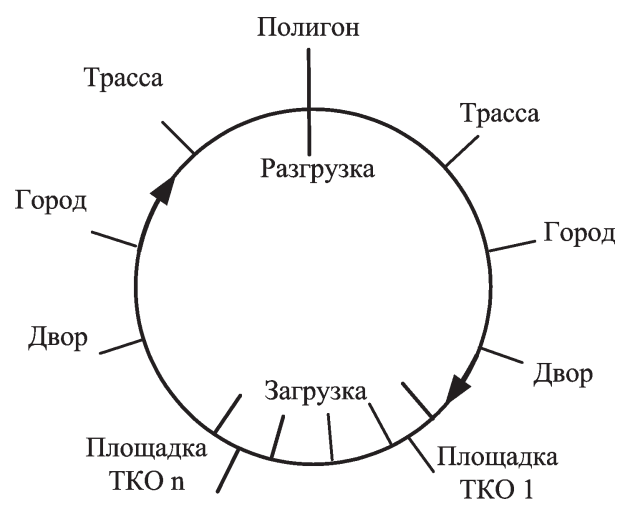

Рис. 3. Цикл оборота парка мусоровозов Источник. Авторская разработка.

полигона, выезжает на трассу, затем въезжает в город, подъезжает к району своего обслуживания. Мусоровоз маневрирует между блоками (площадками) контейнеров, пока не загрузится полностью, затем едет разгружаться на полигон. Проиллюстрируем принцип расчета затраченного времени на круг - от полигона до полигона.

Допустим, емкость мусоровоза равна 18 м $^{3}$. Евроконтейнеры установлены во двоpax блоками, по 3 контейнера на площадке. При заданной емкости мусоровоза $18 \mathrm{~m}^{3}$ и принятом среднем коэффициенте уплотнения 4,5 в данный мусоровоз помещается $18 \cdot 4,5 / 1,1=73,6$ контейнера, где $1,1 \mathrm{~m}^{3}-$ емкость евроконтейнера. Чтобы загрузить такое их количество, мусоровоз вынужден объехать 73,6/3=24,5 площадок из трех контейнеров каждый. Затраченное время включает подготовку к погрузке блока, время погрузки каждого контейнера, а также время маневрирования во дворах. В общем виде длительность рейса и, следовательно, коэффициент оборота парка определяются длительностью погрузки-разгрузки, которая зависит от емкости мусоровоза, а также длительностью маршрута. Эта величина одинакова для всех мусоровозов, за исключением стадии проезда между площадками TКО во дворах: чем больше контейнеров помещается в машину, тем дольше будет стадия ее маневрирования во дворах. В нашем примере принято, что среднее расстояние между площадками ТКО во дворах составляет 300 м, скорость движения 7 км / ч, за круг машина объезжает 24,5 площадок - затраченное время на маневрирование во дворах составит 1,05 часа (табл. 3). 
Расчет коэффициента оборота парка

\begin{tabular}{|c|c|c|c|c|}
\hline Стадия & Шаг & $\begin{array}{c}\text { Время } \\
\text { на } 1 \text { контейнер, } \\
\text { мин. } \\
\end{array}$ & $\begin{array}{c}\text { Время } \\
\text { на } 1 \text { блок, } \\
\text { мин. }\end{array}$ & Время на рейс, мин. (час.) \\
\hline \multirow{4}{*}{ 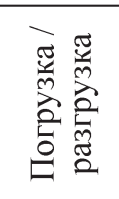 } & $\begin{array}{c}\text { Подготовка к погрузке блока } \\
\text { контейнеров }\end{array}$ & - & 1,5 & $1,5 \cdot 24,5=36,8(0,614)$ \\
\hline & Погрузка 1 контейнера & 1 & 3 & $3 \cdot 24,5=73,5(1,227)$ \\
\hline & Разгрузка машины & - & - & $3(0,05)$ \\
\hline & Итого & - & - & $113,3(1,89)$ \\
\hline \multirow{6}{*}{ 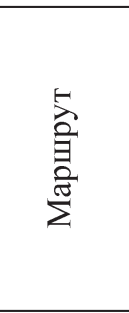 } & Шаг & $\begin{array}{c}\text { Среднее } \\
\text { расстояние, км }\end{array}$ & $\begin{array}{c}\text { Средняя } \\
\text { скорость, км/ч }\end{array}$ & Время на маршрут, час. \\
\hline & Проезд дворов & $0,3 \cdot 24,5$ & 7 & 1,05 \\
\hline & Езда по городу & $15 \cdot 2=30$ & 40 & 0,75 \\
\hline & Езда по трассе & $9,8 \cdot 2=19,6$ & 80 & 0,245 \\
\hline & Проезд полигона & $0,7 \cdot 2=1,4$ & 20 & 0,07 \\
\hline & Итого & 58,4 & - & 2,12 \\
\hline \multicolumn{4}{|c|}{ Общая длительн } & $1,89+2,12=4,0$ \\
\hline
\end{tabular}

Источник. Авторская разработка.

При 8-часовом рабочем дне и длительности одного рейса 4 часа коэффициент оборота парка будет равен 2 рейсам за день. При этих условиях число мусоровозов в парке окажется равным:

$$
\mathrm{Ч}_{\mathrm{MB}}=\frac{\mathrm{Ч}_{\mathrm{MB}}^{\mathrm{roH}} \cdot k_{\text {НнО }}}{313 \cdot k_{\text {ОП }} \cdot k_{\text {ИП }}}=\frac{66441 \cdot 1,25}{313 \cdot 2 \cdot 0,85}=156 ш \text { шт, }
$$

но эта величина получена только для мусоровоза объемом $18 \mathrm{~m}^{3}$.

Расчеты длительности рейса и коэффициента оборота парка для других типов мусоровозов приведены на рис. 4. Здесь же по-
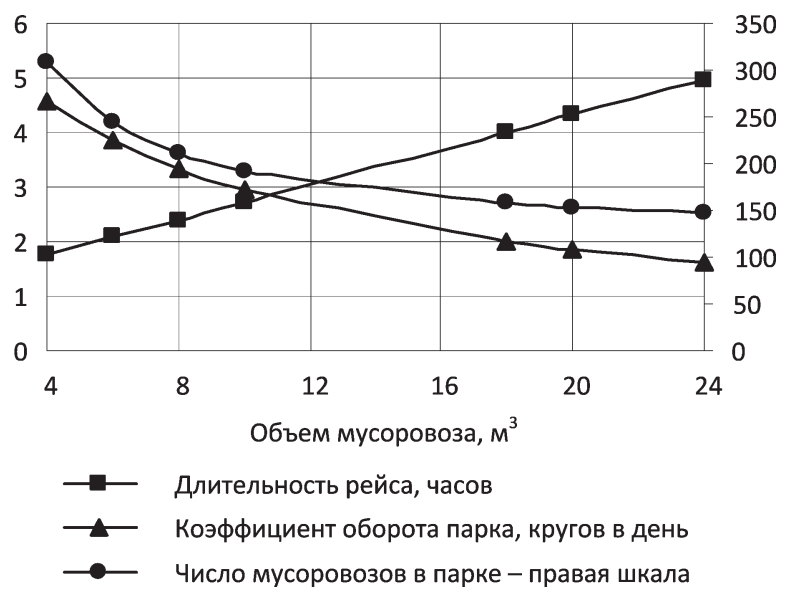

Рис. 4. Длительность рейса, коэффициент оборота парка и расчетный размер парка для различных типов мусоровозов

Источник. Авторская разработка. казано расчетное число мусоровозов в парке. Как видно, для своевременного вывоза мусора из г. Минска с принятым коэффициентом неравномерности образования отходов в 1,25 и коэффициентом использования парка в 0,85 число мусоровозов в парке составит от 150 до 300 единиц. Если использовать большие машины с бункером 24 м $^{3}$, тогда их число составит 150, каждая машина будет делать менее 2 рейсов за смену. Если использовать машины емкостью $4 \mathrm{~m}^{3}$, потребуется более 300 таких машин, каждая за смену сделает свыше 5 рейсов до полигона и обратно. Чем больше объем бункера машины, тем выше ее цена, но тем ниже расходы на эксплуатацию, включая расходы на оплату труда водителей.

Объем мусоровоза оказался важнейшим фактором, от которого зависят не только технико-экономические показатели, но и общий результат - стоимость вывоза мусора на 1 чел. в месяц.

Расчет стоимостных показателей вывоза мусора. Общая стоимость вывоза мусора из г. Минска определяется следующими факторами.

1. Число мусоровозов в парке $Ч_{\mathrm{MB}}$, от которого, в свою очередь, зависят следующие статьи затрат:

- амортизационные отчисления и стоимость ремонтов, связаны с первоначальной стоимостью машин и сроком службы, составляют, по нашим расчетам, от 11 до 
40 тыс. руб. в год, в зависимости от типа и марки мусоровоза;

- расходы на топливо - 18-37 тыс. руб. в год на 1 машину;

- фонд оплаты труда водителя, с отчислениями, принят 44 тыс. руб. в год, при 6 -дневном рабочем дне и 1 водителе на мусоровоз.

2. Стоимость эксплуатации контейнеров, которая равна расчетному числу контейнеров (15 649), умноженному на цену (570 руб./шт.) и деленному на срок службы (принят 3 года).

3. Оплата захоронения/переработки отходов на полигоне или мусоросортировочном заводе, принят усредненный тариф в 10 руб. за 1 т.

4. Административно-управленческие расходы, приняты в 15\% от фонда оплаты труда.

5. Плановая рентабельность, принята в 30\% от выручки.

6. НДС и налог на прибыль.

Расчеты показывают, что для типа мусоровоза с объемом 18 м ${ }^{3}$ условно-расчетная себестоимость вывоза мусора составит 22,9 млн руб. в год; выручка с учетом НДС - 36,7 млн руб. в год, а стоимость оплаты в расчете на одного жителя г. Минска - 1,52 руб. на 1 чел. в месяц. Структура доходов и затрат при данном значении тарифа показана на рис. 5 .

Тариф на вывоз мусора в расчете на одного жителя при использовании мусоровозов различного объема приведена на рис. 6 .

График показывает, что приобретать мусоровозы объемом свыше $24 \mathrm{~m}^{3}$ эконо-

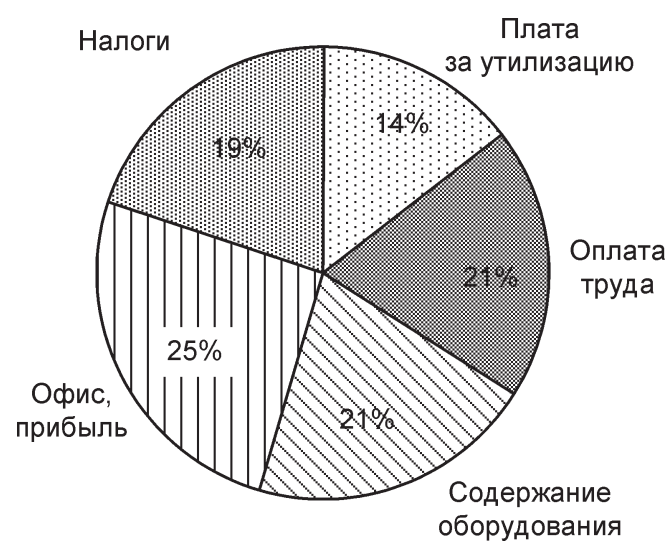

Рис. 5. Структура доходов и затрат на вывоз мусора

Источник. Авторская разработка.

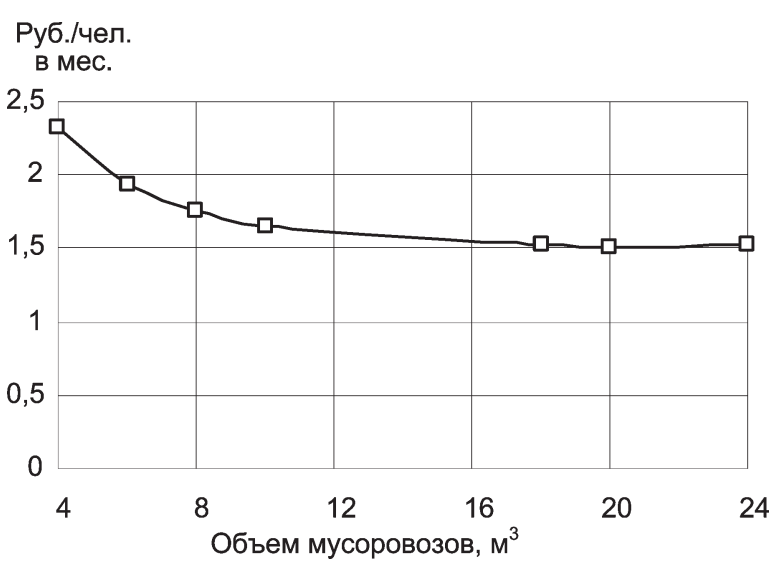

Рис. 6. Расчетная плата за вывоз мусора жителем г. Минска при использовании разных типов мусоровозов

Источник. Авторская разработка.

мически нецелесообразно. При увеличении объема мусоровоза свыше $18 \mathrm{~m}^{3}$ экономия не растет. Это в большей степени вывод для производителей, однако касается он исключительно условий г. Минска. Затраты парка заметно увеличиваются при использовании мусоровозов малой емкости, менее $10 \mathrm{~m}^{3}$. Применение мусоровозов малой емкости оказалось бы экономически оправданным, если бы в г. Минске размещались мусороперегрузочные станции.

В данном примере принята рентабельность в $30 \%$. Попробуем смоделировать ситуацию и оценить, как изменится рентабельность оператора по вывозу отходов при изменении тарифа. Результаты показаны на рис. 7.

В зависимости от состава автопарка оператора безубыточным окажется тариф в размере 1,2 руб./чел. в год. При увеличе-

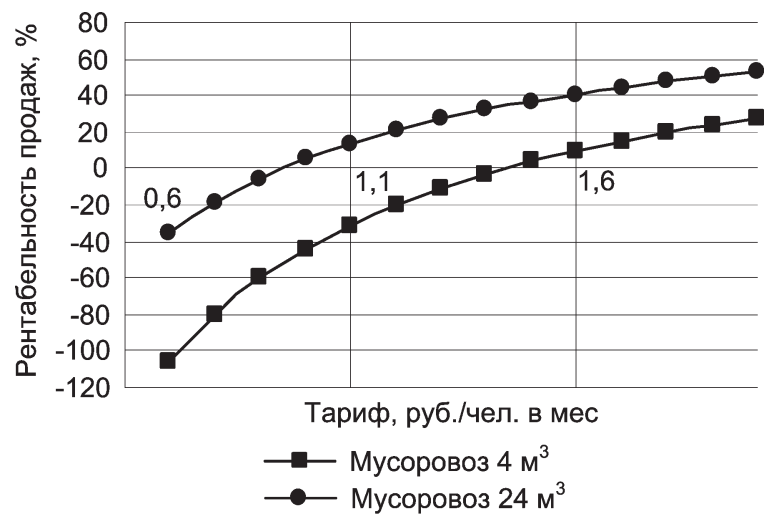

Рис. 7. Чувствительность рентабельности оператора к изменению тарифа

Источник. Авторская разработка. 
нии тарифа свыше 2 руб. расчетная рентабельность достигнет 25-50\%. В действительности сумма оплаты за вывоз мусора определяется фактическими затратами, которые носят сезонный характер и составляют 1,4-2 руб. на 1 чел. При таких тарифах операторы имеют высокий уровень рентабельности, а большинство жителей вряд ли заметят большую разницу в своей жировке даже при увеличении тарифа за вывоз мусора до 4-5 руб. в месяц.

Проведенные расчеты позволили оценить структуру затрат оператора, при этом почти $80 \%$ затрат связано с содержанием парка мусоровозов, оплатой труда; стоимость тарифа на утилизацию или переработку мусора составляет $21 \%$ от общей себестоимости. Структура затрат оператора объясняет, почему в г. Минске не ведется полноценный раздельный сбор мусора. Сегодня мусор из контейнеров для раздельного сбора сгружают в одну машину и везут на полигон, где проводят его сортировку. Для раздельного сбора нужно в 2-3 раза увеличить число рейсов и число контейнеров, при этом себестоимость вырастет более чем в 2 раза. Сортировка на полигоне обойдется дешевле, даже если повысить плату за утилизацию с 10 до 80100 руб. за 1 т. Примерно столько составляет налог на захоронение отходов в Латвии, Эстонии и Польше. В Великобритании он еще выше, превышает 250 руб. за 1 т, а в Литве примерно соответствует нашему уровню, 3 евро за тонну.

Существенное увеличение налога на захоронение отходов в Беларуси могло бы стимулировать операторов к организации реального раздельного сбора отходов, но в этом случае пришлось бы увеличить тариф в 2-4 раза, до 4-6 руб. на 1 чел. в месяц.

Сферой применения предложенного инструментария не обязательно должен быть весь г. Минск. Примерную оценку общих затрат на вывоз мусора можно рассчитать по количеству жителей конкретного административного района или микрорайона. Для других населенных пунктов Беларуси ряд технико-экономических показателей придется пересчитать в соответствии с преобладающим способом утили- зации отходов, отдаленностью полигона от города и размером населенного пункта.

Масштаб отрасли обращения с ТКО невелик, и его можно оценить косвенно по расходам домохозяйств. Если каждый житель Беларуси платит за вывоз мусора около 2 руб./мес., то ежегодная сумма расходов составит примерно 240 млн руб. Добавим сюда еще затраты организаций, которые образуют несколько меньший объем ТКО, чем граждане, получим максимум 500 млн руб. - эта сумма соответствует годовой выручке не самого крупного предприятия. Небольшие масштабы отрасли во многом объясняют дефицит методического обеспечения для расчетов и принятия решений. Учитывая стремление Беларуси к достижению ЦУР, такое методическое обеспечение нужно разрабатывать. В приведенных примерах показано, что его научная основа должна базироваться не только на разработках в сфере экологии и экономики природопользования, но и на методологии и инструментарии пространственной экономики, транспортной логистики. Бизнес-процессы по обращению с коммунальными отходами могут быть описаны и оптимизированы с использованием стандартных и новых подходов данных научных направлений.

Остается актуальным вопрос нормирования технико-экономических показателей в сфере обращения с отходами, поскольку c момента обоснования действующих нормативов прошло много лет. При нормировании необходимо учитывать изменившиеся технологии сбора и утилизации отходов, но можно применять и традиционные методы, к примеру хронометраж времени погрузочно-разгрузочных работ.

\section{СПИСОК ЛИТЕРАТУРЫ (REFERENCES)}

Гаджинский A.M. 2004. Выбор места расположения склада. Справочник экономиста. № 8. URL: https://www.profiz.ru/se/8_2004/mesto_sklada/ [Gadzhinsky A.M. 2004. Choosing a warehouse location. Spravochnik ekonomista. No 8. (In Russ.)]

Гибадуллин А.А. 2015. Минимальная охватывающая окружность. Научные исследования. № 1. C. 6-7. [Gibadullin A.A. 2015. Minimum girth. Nauchnye issledovaniya. No 1. PP. 6-7. (In Russ.)]

Губернаторов А.М., Ломов Е.Е. 2020. Экономические аспекты управления твердыми ком- 
мунальными отходами: российская зарубежная практика. Вестник Алтайской академии экономики и права. № 5. С. 278-284. [Gubernatorov A.M., Lomov E.E. 2020. Economic aspects of solid municipal waste management: Russian and foreign practice. Vestnik Altayskoy akademii ekonomiki $i$ prava. No 5. PP. 278-284. (In Russ.)]

Дулесов А.С., Прутовых М.А. 2012. Алгоритмы территориального размещения предприятий на основе геоинформационных технологий. Прикладная информатика. № 5. С. 14-21. [Dulesov A.S., Prutovykh M.A. 2012. Algorithms for the territorial distribution of enterprises based on geoinformation technologies. Prikladnaya informatika. No 5. PP. 14-21. (In Russ.)]

Дулесов А.С., Прутовых М.А. 2013. Методика решения задачи об оптимальном размещении производственных объектов. Современные проблемы науки и образования. № 5. C. 151. [Dulesov A.S., Prutovykh M.A. The method of taskrs solution about optimum siting of production objects. No 5 . P. 151. (In Russ.)]

Сачек П., Точицкая И., Батова Н. 2018. Замыкая круг: законодательное стимулирование внедрения циркулярной экономики. BEROC Green Economy Policy Paper Series, PP GE. No 4. 24 c. URL: https://beroc.org/publications/policy_papers/ zamykaya-krug/ [(In Russ.)]

Сысоев С. 2020. Обзор систем сбора и обработки муниципальных отходов в Швеции и Финляндии. BEROC Green Economy Policy Paper Series, PP. No 16. URL: https://beroc.org/publications/ policy_papers/obzor-sistem/[(In Russ.)]

Шершунович Е., Точицкая И. 2018. Статистика отходов в Беларуси: узкие места и широкое поле для деятельности. BEROC Green Economy Policy Paper Series, PP GE. No 2. 14 c. URL: http:// beroc.ipm.by/upload/iblock/184/18444a 51289184031f2dbeeeea1dbc74.pdf [(In Russ.)]

\title{
ON THE ECONOMIC GROUNDING OF DECISIONS RELATED TO THE COLLECTION OF MUNICIPAL SOLID WASTE
}

\author{
Maria Tsvil ${ }^{1}$ \\ Author affiliation: ${ }^{1}$ Contact office of the Republic of Belarus (Qingdao, PRC). \\ Corresponding author: Maria Tsvil (belaruscn@vip.sina.com).
}

ABSTRACT. A number of author's methods for calculating economic indicators related to the collection and removal of solid municipal waste have been proposed. The peculiarity of the methods lies in the application of some approaches of spatial economics for linking economic indicators to the urban landscape. In particular, the possibilities of using geographic coordinates in the calculations are considered in order to optimize the location of objects, assess the distances, the speed of movement, the time spent in the process of collecting and transporting municipal waste to the landfill. For input-output of geographical coordinates of objects, the Yandex Maps application was used. In the process of applying the methods, using several examples, the cost of removing municipal waste from the city of Minsk per capita was established, and the main factors influencing the change in this indicator were determined.

KEYWORDS: municipal solid waste, spatial economics, time rationing.

JEL-code: Q53, R41, R53.

DOI: $10.46782 / 1818-4510-2021-4-72-88$ 